\title{
Can Financial Development Improve Energy Efficiency? Based on SBM-Undesirable Model and Fuzzy-Set Qualitative Comparative Analysis
}

\author{
Chao Li ${ }^{1}$, Panpan $\mathrm{Li}^{2 *}$, Peng Bi ${ }^{3}$, Feihong Yun ${ }^{1}$, Lei Gao ${ }^{4}$ \\ ${ }^{1}$ College of Mechanical and Electrical Engineering, Harbin Engineering University, Harbin 150001, China \\ ${ }^{2}$ School of Economics and Management, Harbin Engineering University, Harbin 150001, China \\ ${ }^{3}$ School of Economics and Management, Jiamusi University, Jiamusi 150007, China \\ ${ }^{4}$ School of Economics and Management, Beijing Forestry University, Beijing 100083, China
}

Received: 21 July 2020

Accepted: 28 November 2020

\begin{abstract}
To explore the effect of financial development on energy efficiency is of guiding significance for grasping China's energy situation and making fiscal policies. First, this paper considers the environmental pollution into the output variables, and builds an SBM model to evaluate the energy efficiency. Second, this paper explores the dual effect of financial development on energy efficiency, and based on the interaction characteristics of multiple factors, the configuration of energy efficiency is discussed by using fsQCA method. The results are as follows: there are obvious differences in energy efficiency in different regions, with a declining trend from eastern to western. Regions that achieve high energy efficiency tend to have better financial development and industrial structure. When financial development and industrial structure are relatively good, regions should consider the role of FDI and give full play to its spillover effect. Regardless of financial development, regions should steadily achieve economic growth, attach importance to innovation input and correctly guide foreign investment.
\end{abstract}

Keywords: energy efficiency, financial development, configurational thinking, SBM-undesirable model, fsQCA

\section{Introduction}

Long-term adoption of extensive economic development model to promote rapid development, energy issues have become a bottleneck restricting china's economic development [1]. Improving energy efficiency has become an inevitable choice for alleviating the contradiction between energy supply and demand and reducing environmental pressure. The Green Finance plan proposed by the Chinese government at the G20 summit, the role of financial means in realizing the socio-economic environment has been clarified. Therefore, exploring the effect of financial development on energy efficiency and the ways to improve energy efficiency have important significance for grasping the actual situation of energy efficiency in China. 
The effect of financial development on energy efficiency has mixed results $[2,3]$. The reasons are as follows: First, there are different energy efficiency measurement methods. Second, the existing researches focus on the direct effect of financial development on energy efficiency, but ignore the indirect effect. Third, the existing methods are mainly analysis the net effect of factors, and ignore the matching effect. Therefore, it seems important to measure energy efficiency in a more reasonable way, analyzes the dual effect of financial development on energy efficiency, and adopts a more matching method to analyze this relationship. Therefore, this paper carries out the following research: First, the SBM-undesirable model is used to measure energy efficiency and clarifies the state of energy efficiency in China. Second, analyze the dual effect of financial development on energy efficiency, and build an analysis framework for the influencing factors. Third, the fuzzy set qualitative comparative analysis method is used to explore the matching effect of influencing factors on energy efficiency.

The purpose of this paper is to clarify the development status of regional energy efficiency and its promotion path. The contributions are as follows: First, this paper treats environmental issue as undesired output, and uses the SBM-undesired model to solve the situation where multiple decision units may be effective at the same time. Second, this paper adopts fsQCA method to explore the matching effect of multiple factors on energy efficiency and finds multiple equivalent paths to improve energy efficiency, expands research methods, and further clarifies the effect of financial development on energy efficiency.

\section{Literature Review}

\section{Energy Efficiency Evaluation}

Energy efficiency evaluation focuses on the following aspects: First, the regional level and industry level. Lin and Liu conducted research from the perspective of China's provinces [4]. Zhang et al. conducted research on the China's aviation industry and China's public service industry, respectively [5]. Second, research on total factor energy efficiency considering undesirable output. Wang et al. incorporated $\mathrm{CO}_{2}$ into the energy efficiency evaluation as an unwanted output [6]. Third, Tobit model is used to analyze the influencing factors of energy efficiency [7]. Liu et al. used Tobit model to investigate the influence of economic growth, energy structure and other factors on energy efficiency [8].

These studies provide reference for energy efficiency evaluation, but there are deficiencies, the frontier measurement method based on directional distance function, which ignores that multiple decision units may be simultaneously effective, impossible to distinguish and order these decision units.

\section{The Influencing Factors of Energy Efficiency}

Scholars have focused on the effect of financial development [9, 10], FDI [11], industrial structure [12], economic growth [8] and others on energy efficiency, and VAR model, Dumitrescu-Hurlin panel causality test and others were used to test [12, 13, 14]. Zhang et al. explored the impact of market openness, energy prices and industrial structure on energy efficiency [15]. Liu et al. explored the impact of economic growth, industrialization and energy structure on energy efficiency [8]. Bi et al. found that environmental regulation positively affected energy efficiency of China's thermal power industry [16].

These researches have reference significance, but some aspects need to be improved. First, there is no research framework of influencing factors based on the same perspective. Second, the methods mainly explore the "net effect" of individual factor, or the moderating effect and intermediary effect of up to three variables, it could not answer the synergies among factors.

\section{Financial Development and Energy Efficiency}

Scholars have focused on the role of financial development in addressing environmental change, especially energy consumption [17]. Le et al. emphasized that financial development derived renewable energy consumption [3]. Chen et al. revealed that financial development affected the energy intensity of non-OECD countries [2]. Besides, financial development involves multiple actors, so a comprehensive index covering many aspects of financial development is needed [17]. Previous studies focused on the effect of financial development on energy efficiency [18]. Xu and Tan indicated that financial development affected resource utilization efficiency [19].

These studies contribute to the further study, but there are some deficiencies: first, the indirect effect of financial development is ignored. Second, existing literatures focus on the measurement of financial development from scale perspective, and ignore financial efficiency.

\section{Theoretical Background}

\section{Evaluation of Energy Efficiency}

Energy efficiency refers to using less energy to provide the same amount of services or useful output [20]. It obtains more output under the premise of consuming less energy, and reduce energy consumption through changes in technological progress and lifestyle factors [21]. The Eighteenth National Congress of the Communist Party of China put forward the strategic thinking of "energy revolution" to achieve sustainable development of economy-energyenvironment. Therefore, energy efficiency evaluation 
should consider economy, energy and environment comprehensively, and achieve maximum economic benefits with minimum energy consumption and environmental pollution, which is consistent with the "economic-energy-environment" coordinated strategy.

Single factor energy efficiency emphasizes the uniqueness of input factors, uses the ratio of energy input and economic output to measure, and has the advantages of intuitiveness and easy calculation [22]. However, it has certain limitations: it is impossible to accurately reflect the effect of energy input on economic output. Total factor energy efficiency takes into account capital, labor, energy and other factors, the result can more accurately and objectively reflect the efficiency level of economic activities [4]. Meanwhile, to accurately measure energy efficiency, environmental factors must be combined with total factor energy efficiency [6]. Many scholars use air pollution to measure environmental pollution. This paper believes that the energy input-output process is a complex system, besides air pollution, it also produces water pollution and solid waste pollution. Furthermore, when undesired outputs are included in measurement, there may be multiple simultaneously valid decision units.

According to the above research, this paper considers the undesired output in the production process, and incorporates wastewater, waste gas, and solid waste emissions into output variables, and uses the SBM-Undesirable model to solve the situation where multiple decision units may be simultaneously effective.

\section{Dual Effect of Financial Development on Energy Efficiency}

Financial development refers to the degree of financial development reflected by a country's current financial institutions and tools [23]. The process of financial function upgrade is regarded as the process of financial development, which reflects the dynamic evolution from scale to efficiency. Therefore, this paper measures the financial development from financial scale and financial efficiency, analyzes the dual effect of financial development on energy efficiency, and constructs the analysis framework.

\section{Direct Effect of Financial Development on Energy Efficiency}

Financial development directly affects energy efficiency. Financial development can provide financial support for innovative development and reduce information asymmetry, which is conducive to improve resource allocation efficiency [24]. The expansion of financial scale can help enterprises to obtain financial resources more efficiently and inexpensively, which generate business effects, help enterprises to expand existing business scale and affect the use of energy goods [25]. Financial system can mobilize savings, create funds for expansion, which enhance enterprises' confidence and expand economic scale, ultimately affect energy consumption [26].

\section{Indirect Effect of Financial Development on Energy Efficiency}

Financial development affects energy efficiency through FDI. If the financial development is low and the amount of capital is insufficient, it is difficult for enterprises to obtain external financing, while FDI can alleviate this problem and enable projects that cannot be implemented due to insufficient funds, thereby driving domestic investment [27]. A sound financial system delivers market information to foreign investors, which increases investment confidence and attracts the inflow of FDI [28]. Meanwhile, FDI brings advanced technologies [29] and drives enterprises to expand existing businesses or build new factories [11], which affects green innovation and energy utilization.

Financial development affects energy efficiency through industrial structure. The expansion of financial scale minimizes the financing transaction costs and information asymmetry, and through interests guide mechanism, capital can be invested in strategic emerging industries, emerging technologies industries [30]. Effective information disclosure can guide investors to subscribe for shares in high-quality industries, and then guide the industrial structure to a healthy direction [31]. Besides, industrial structure adjustment is an effective way to achieve green economy growth, which promotes production factors transformation from non-cleaner production industries to cleaner production industries [12].

Financial development affects energy efficiency through innovation input. It is indispensable for innovation activities to seek capital support from the financial market [32]. The expansion of financial scale drives capital accumulation and innovation investment [33], and financial system guides industries to invest in innovation activities for new products and services. Meanwhile, financial institutions evaluate intangible assets as the main R\&D assets, thus alleviate enterprises' financing constraints [34]. Besides, as an important factor to promote technological progress, innovation input significantly affects energy utilization and allocation.

Financial development affects energy efficiency through economic growth. Financial industries can improve operating efficiency and economic benefits, expand market transaction scale, and thereby improve overall economic growth [35]. Asteriou and Spanos found that financial development promoted economic growth [36]. Besides, there is a mutual influence between economic growth and energy consumption [25]. Energy consumption is the driving force of income, and the economy needs to use energy resources. Therefore, improving energy efficiency is important for increasing economic income. 
Management problem is a complex causal relationship of "multiple factors leading to the same result" [37]. "How to achieve high energy efficiency often requires comprehensive consideration of multiple factors". The influencing factors of energy efficiency are not independent, while play a synergistic role through matching effect. Therefore, this paper discusses how influencing factors impact energy efficiency through matching effect. Fig. 1. shows the research framework.

\section{Methodology, Variables and Data Source}

$$
\text { Methodology }
$$

\section{SBM-Undesirable Model}

Data envelopment analysis (DEA) is an evaluation method that studies the relative efficiency among organizations of the decision unit with multiple inputs and multiple outputs. According to the data to determine the possible production set, compare a single decision unit with the determined optimal production frontier, the relative efficiency of the decision unit is calculated. This method has two advantages: first, it can calculate the input and output indicators of different unit, without nondimensionalizing the data. Second, the optimal weight of unit is calculated from the original data without the assumption of weight in advance. However, when evaluating the relative efficiency of traditional DEA models (CCR, BCC), we hope to maximize the output while reducing the input as much as possible. There are undesirable outputs in production activities, such as waste water, exhaust gas, and solid waste, which lead to many environmental problems. To solve this problem, Tone proposed a SBM-Undesirable model, which measured the relationship between input and output. This paper uses SBM-Undesirable model to measure energy efficiency. The specific model is as follows.

Assuming that there are $n$ decision units, $\mathrm{m}$ input indicators, $\mathrm{s}_{1}$ expected outputs, and $\mathrm{s}_{2}$ undesired outputs, the input matrix $X$, expected output matrix $Y^{\mathrm{g}}$, and unexpected output matrix $\mathrm{Y}^{\mathrm{b}}$ are:

$$
\begin{aligned}
& X=\left(\mathrm{x}_{1}, \ldots, \mathrm{x}_{n}\right) \in R^{m \times n}, X>0 \\
& Y^{g}=\left(y_{1}^{g}, \ldots, \mathrm{y}_{n}^{g}\right) \in R^{s_{1} \times n}, Y^{g}>0 \\
& Y^{b}=\left(y_{1}^{b}, \ldots, \mathrm{y}_{n}^{b}\right) \in R^{s_{2} \times n}, Y^{b}>0
\end{aligned}
$$
be P:

The production set composed of decision units may

$$
P(x)=\left\{\left(x, y^{g}, y^{b}\right) \mid x \geq \lambda X, Y^{g} \leq \lambda Y^{g}, y^{b} \leq \lambda Y^{b}, \lambda \geq 0\right\}
$$

The mathematical form of SBM-Undesirable model:

$$
\begin{gathered}
\rho^{*}=\min \frac{1-\frac{1}{m} \sum_{i=1}^{m} \frac{s_{\bar{i}}}{x_{i 0}}}{1+\frac{1}{s_{1}+s_{2}}\left(\sum_{r=1}^{s_{1}} \frac{s_{r}^{g}}{y_{r 0}^{g}}+\sum_{r=1}^{s_{2}} \frac{s_{r}^{b}}{y_{r 0}^{b}}\right)} \\
x_{0}=\lambda X+s^{-} \\
y_{0}^{g}=\lambda Y^{g}-s^{g} \\
y_{0}^{b}=\lambda Y^{b}-s^{b} \\
s^{-} \geq 0, s^{g} \geq 0, s^{b} \geq 0, \lambda \geq 0
\end{gathered}
$$

$\rho^{*}$ is the objective function value, $s^{-}$is the relaxation variable of the input indicator, $s^{g}$ and $s^{b}$ are the slack variables of expected output and undesired output respectively. If $\rho^{*}=1$ and $s^{-}=s^{g}=s^{b}=0$, the decision unit is valid, otherwise, the decision unit is invalid, and there is room for improvement in input or output.

\section{Qualitative Comparative Analysis Method}

The qualitative comparative analysis method is based on the holistic perspective, using Boolean algebra algorithm to solve complex social problems induced by multiple causes [38], and exploring the combination of causes leading to social problems, in line with the inter-dependence and causal complexity of management practice [39]. The reliability of results is measured by coverage and consistency. It is calculated as follows:

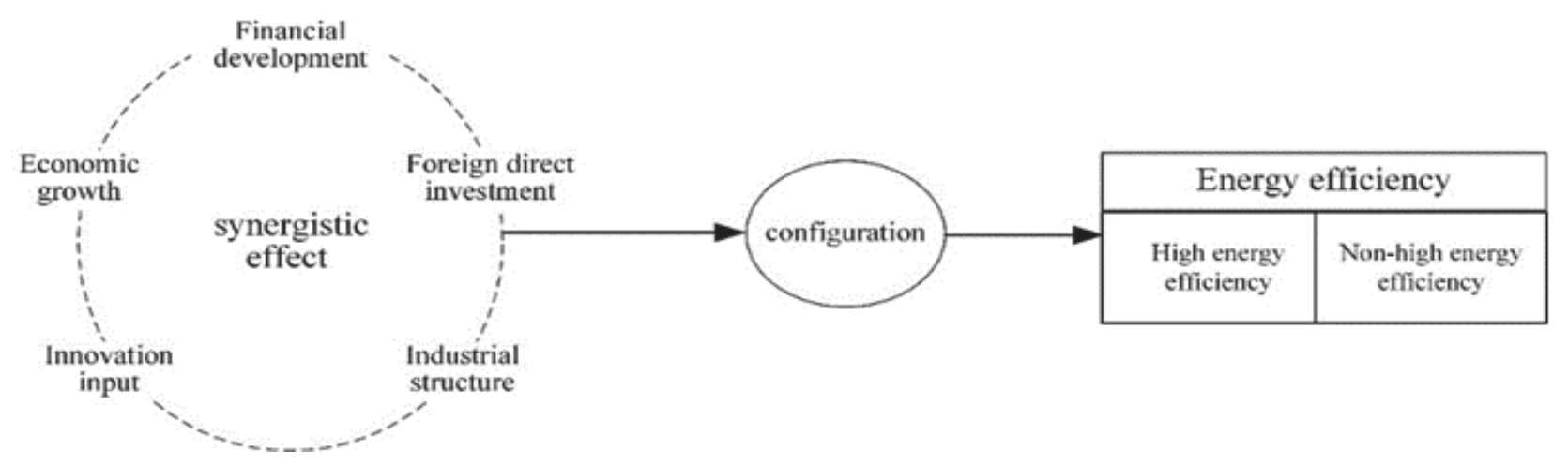

Fig. 1. Research framework. 


$$
\begin{gathered}
\text { Coverage }\left(X_{i} \leq Y_{i}\right)=\sum\left(\min \left(X_{i}, Y_{i}\right)\right) / \sum Y_{i} \\
\text { Consistency }\left(X_{i} \leq Y_{i}\right)=\sum\left(\min \left(X_{i}, Y_{i}\right)\right) / \sum X_{i}
\end{gathered}
$$

...where, $X_{i}$ represents the degree of membership of the it-ch case in condition $X$. $Y_{i}$ represents the membership of the $\mathrm{i}$-th case in the result $\mathrm{Y} . \min \left(\mathrm{X}_{\mathrm{i}}, \mathrm{Y}_{\mathrm{i}}\right)$ indicates the minimum value of $X_{i}$ and $Y_{i}$. The closer the value of Consistency $(\mathrm{X} \leq \mathrm{Y})$ is to 1 , the greater the certainty that the $\mathrm{X}$ set belongs to the $\mathrm{Y}$ set. The closer the value of Coverage $(X \leq Y)$ is to 1 , it means that the less likely the non-X set also belongs to the $\mathrm{Y}$ set.

This paper adopts fsQCA method for the following reasons: First, the difference in energy efficiency is caused by matching effect of factors. QCA focuses on digging out the similar or different factor configurations that have explanatory power on the result and are composed of factors [40]. Second, number of research samples. The samples are 30 provinces in China, which cannot meet the "large sample" demand of quantitative research, and the case cannot be compared manually. While QCA results depend on whether the sample covers representative sample and do not require treatment of different levels of factors [41]. Third, fsQCA method considers the subtle effects of varying degrees of factors on the result. China has a vast territory and distinct regional characteristics, assigning variables to continuous fuzzy sets in the interval $[0,1]$ is accordance with reality, which makes up for the shortcomings of binary assignment [40].

\section{Variables}

\section{Energy Efficiency}

Input variables. (1) Capital input. The total fixed asset investment of the whole society is selected as the proxy index. (2) Labor force. The employed population at the end of each year as the measurement index. (3) Energy consumption. Regional total energy consumption as proxy indicator [42].

Output variables. (1) Expected output. Labor, capital, and energy inputs are ultimately reflected in GDP. Therefore, this paper selects the GDP of each region as a measure index. (2) Unexpected output. The waste water discharge, waste gas discharge and solid waste discharge are selected as indicators [43].

\section{Financial Development}

Due to China's financial system has been dominated by bank and difficulty in obtaining data of the securities market, this paper comprehensively measures the financial development from financial scale and financial efficiency. Specifically, the financial scale is measured by the deposits and loans of financial institutions per unit of GDP. Financial efficiency is measured by such indicators as financial practitioners, total market value of stocks and fixed asset investment in the financial sector [44]. Finally, the comprehensive value is obtained through Max-Min standardization.

\section{Foreign Direct Investment}

FDI can bring new technologies and clean production methods to the host country, but it may also increase the environmental pressure [45]. This paper adopts the foreign direct investment at the end of the year as the proxy indicator [46].

\section{Industrial Structure}

Promoting the development of the tertiary industry, which can realize the rapid growth of the industry and green innovation. The secondary industry is the major sector of energy consumption and pollution emissions [47]. Therefore, this paper adopts the ratio of the gross product of the tertiary industry and gross domestic product to measure [48].

\section{Innovation Input}

Innovation input is the fundamental guarantee for improving innovation capacity and enhancing economic growth. Innovation input covers innovation personnel and innovation capital, this paper uses the R\&D personnel and internal expenditure of $R \& D$ funds as the proxy indicator [49], and used the Max-Min standardization to obtain the comprehensive value.

\section{Economic Growth}

As we all know, GDP per capita is an important indicator of economic growth [26], so it does not need to be explained in detail like other variables.

\section{Data Source}

According to the availability of data, this paper selects 30 provinces in China in 2017 as a sample (the related data missing of Tibet, Hong Kong, Macau, and Taiwan). Specifically, the data of GDP, foreign direct investment, and gross product of the tertiary industry received from the China Statistical Yearbook, the data of energy consumption obtained from China Energy Statistical Yearbook, and the data of innovation input received from China Science and Technology Statistical Yearbook. The indicators of financial development such as the balance of deposits and loans of financial institutions came from the China Financial Statistics Yearbook. The number of employees at the end of the year came from the statistical yearbooks of provinces.

It should be noted that the reason why this paper uses only one year of data to conduct research is to follow the existing research and the fuzzy set qualitative comparative analysis method, which is suitable for the characteristics of cross-sectional data. 


\section{Empirical Analysis}

\section{Energy Efficiency Assessment Results}

This paper uses the SBM-Undesirable model to estimate energy efficiency. The results are shown in Fig. 2. The results indicate that the energy efficiency of different regions varies greatly. Specifically, Beijing, Shanghai, Tianjin, Guangdong have higher energy efficiency, while Qinghai, Xinjiang, Ningxia have lower energy efficiency. In terms of economic regions, the average energy efficiency in eastern is 0.583 , which is higher than the national average of 0.452 , and the average energy efficiency in the central and western regions is 0.388 and 0.320 , respectively, which is lower than the national average. The energy efficiency value gradually decreases from eastern to central and western. The low energy endowment and high energy efficiency in eastern are contrast to the high energy endowment and low energy efficiency in western, which reflects the "resource curse" phenomenon: the western region is dominated by resource industries, with irrational industrial structure, insufficient accumulation of high-end human capital, and serious environmental pollution.

Regional differences in energy efficiency are caused by combined effects of different factors. In the following research, this paper attempts to explore which factors combine to cause high (non-high) energy efficiency.

\section{Results of Fuzzy Set Qualitative Comparative Analysis}

\section{Calibration}

Calibration refers to set a target set according to relevant standards and measures the degree to which each sample belongs to the target set. It is necessary to set three anchor points: full membership threshold, crossover point threshold and non-membership threshold, and the membership degree is among 0-1. As suggested by Fiss [39] and Misangyi [50], this paper sets the upper quartile, mean value, and lower quartile as calibration values, and the calibration process is completed by the direct method [38]. Table 1 shows the calibration anchors.

\section{Necessity Test}

Necessity tests need to be checked before configuration analysis. When consistency exceeds the threshold of 0.9 , which indicates that the factor is the necessary condition for the result [43]. As can be seen from Table 2, the consistency of all factors does not exceed 0.9, indicating that all factors cannot be the necessary condition for high (non-high) energy efficiency.

\section{Configuration Results}

Configuration analysis reveals the sufficiency analysis of results caused by different configurations of multiple factors. By setting the consistency threshold and the case frequency threshold, the less representative configurations were excluded, and the configurations that significantly causes the results were retained. According to research standard, the consistency threshold should not be lower than 0.75, the case frequency threshold should be set according to the number of samples, the small and medium sample frequency should be set to 1 , and the large sample frequency should be greater than 1 [39]. Therefore, this paper sets the consistency threshold to 0.80 and the case frequency threshold to 1 . According to the existing research, intermediate solution only considers simple counterfactual analysis, the results obtained are more reasonable and more realistic, so this solution is finally analyzed [38]. The conditions in parsimonious solution are defined as core conditions, and the conditions that appear in intermediate solution but are eliminated by parsimonious solution are defined as peripheral conditions [39]. Table 3 and 4 present the configuration of high and non-high energy efficiency, respectively.

\section{Energy efficiency}

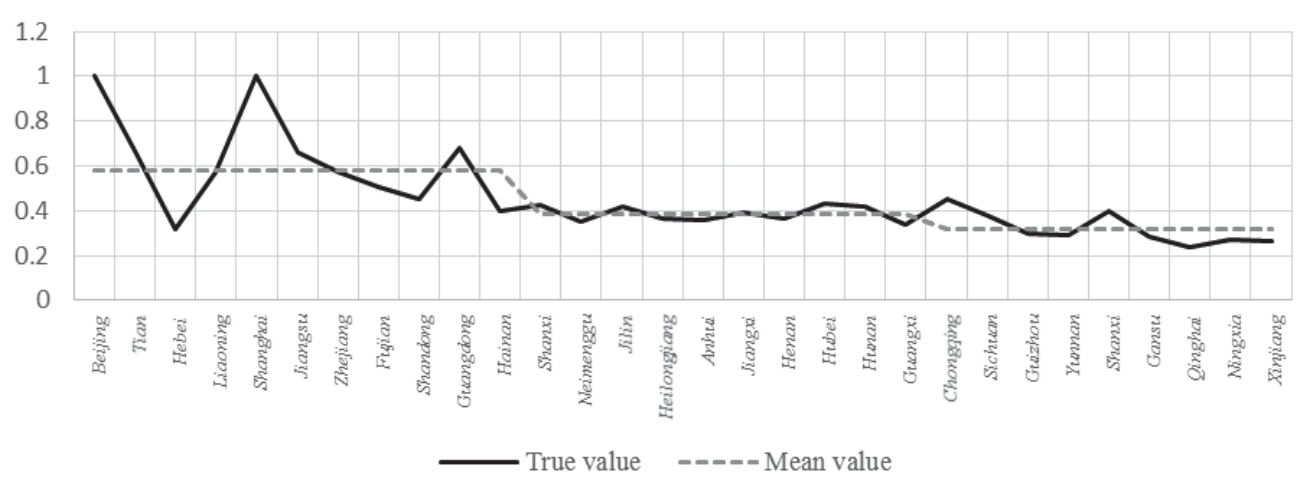

Fig. 2. Energy efficiency of 30 provinces in china in 2017. 
Table 1. Calibration anchors.

\begin{tabular}{|c|c|c|c|c|}
\hline \multirow{2}{*}{ Variables } & \multirow{2}{*}{ Abbreviation } & \multicolumn{3}{|c|}{ Calibration anchors } \\
\cline { 3 - 5 } & & Upper quartile & Mean value & Lower quartile \\
\hline Financial development & FD & 0.8449 & 0.7874 & 0.7079 \\
\hline Foreign direct investment & FDI & 2715.9491 & 905.998 & 385.0074 \\
\hline Industrial structure & IS & 0.5339 & 0.4861 & 0.4528 \\
\hline Innovation input & II & 0.2628 & 0.1704 & 0.0532 \\
\hline Economic growth & EG & 74838.355 & 50161.5 & 43418.6183 \\
\hline Energy efficiency & EE & 0.5200 & 0.3974 & 0.3319 \\
\hline
\end{tabular}

Table 2 . Necessity test.

\begin{tabular}{|c|c|c|c|c|c|}
\hline \multirow{2}{*}{ Variables } & \multicolumn{2}{|c|}{ EE } & \multirow{2}{*}{ Variables } & Consistency & Coverage \\
\cline { 2 - 3 } & Consistency & Coverage & & 0.431 & 0.456 \\
\hline FD & 0.666 & 0.663 & FD & 0.681 & 0.684 \\
\hline$\sim$ FD & 0.453 & 0.428 & $\sim$ FD & 0.312 & 0.337 \\
\hline FDI & 0.849 & 0.862 & FDI & 0.872 & 0.860 \\
\hline$\sim$ FDI & 0.346 & 0.322 & $\sim$ FDI & 0.381 & 0.408 \\
\hline IS & 0.704 & 0.710 & IS & 0.729 & 0.723 \\
\hline$\sim$ IS & 0.413 & 0.385 & $\sim$ IS & 0.346 & 0.364 \\
\hline II & 0.750 & 0.744 & II & 0.757 & 0.763 \\
\hline$\sim$ II & 0.359 & 0.341 & $\sim$ II & 0.286 & 0.311 \\
\hline EG & 0.836 & 0.857 & EG & 0.869 & 0.849 \\
\hline$\sim$ EG & 0.328 & 0.302 & EG & & \\
\hline
\end{tabular}

Notes: $\sim$ indicates the absence of factor

Table 3. Configurations of high energy efficiency.

\begin{tabular}{|c|c|c|c|c|c|}
\hline \multirow{2}{*}{ Variables } & \multicolumn{5}{|c|}{ High energy efficiency } \\
\cline { 2 - 6 } & $\mathrm{H} 1$ & $\mathrm{H} 2$ & $\mathrm{H} 3$ & $\mathrm{H} 4$ & $\mathrm{H} 5$ \\
\hline FD & & $\bullet$ & $\bullet$ & $\bullet$ & $\bullet$ \\
\hline FDI & $\bullet$ & & $\bullet$ & $\bullet$ & $\otimes$ \\
\hline IS & & $\otimes$ & $\bullet$ & $\bullet$ & $\bullet$ \\
\hline II & $\bullet$ & $\bullet$ & $\bullet$ & & $\otimes$ \\
\hline EG & $\bullet$ & $\bullet$ & & $\bullet$ & $\otimes$ \\
\hline Consistency & 0.973 & 0.928 & 0.944 & 0.998 & 0.818 \\
\hline Raw coverage & 0.681 & 0.230 & 0.417 & 0.411 & 0.102 \\
\hline Unique coverage & 0.209 & 0.016 & 0.027 & 0.024 & 0.052 \\
\hline Solution coverage & & \multicolumn{5}{|c|}{0.811} \\
\hline Solution consistency & & \multicolumn{7}{c}{} \\
\hline Notes: $\bullet$ • & & $\bullet 18$ & \\
\hline
\end{tabular}

Notes: $\bullet$ shows the presence of a core condition; • presents the presence of a peripheral condition; $\otimes$ expresses the absence of a core condition; $\otimes$ denotes the absence of a peripheral condition; and blank spaces denote "don't care".
From Table 3, there are 5 configurations can cause high energy efficiency. The consistency of all configurations is higher than 0.8 , indicating that the results are acceptable. The overall coverage is 0.811 , it means that the results explain the reason for $81.1 \%$ of high energy efficiency. Moreover, there are 3 configurations can cause non-high energy efficiency. The consistency of all configurations is higher than 0.8 and the overall coverage is 0.865 . The configurations of non-high energy efficiency is not the opposite of the configurations of high energy efficiency. Meanwhile, different configurations can cause high (non-high) energy efficiency, the configurations have the characteristics of "all roads lead to Rome".

From the results of high energy efficiency, configuration H1 (FDI*II*EG) and H2 (FD* IS*II*EG), innovation input and economic growth play a core role together, while other factors are different. Configuration H3 (FD*FDI*IS*II), H4 (FD*FDI*IS*ED) and H5 (FD*FDI*IS*II*EG), financial development and industrial structure play a core role together, while 
Table 4. Configurations of non-high energy efficiency.

\begin{tabular}{|c|c|c|c|}
\hline \multirow{2}{*}{ Variables } & \multicolumn{3}{|c|}{ Non-high energy efficiency } \\
\cline { 2 - 4 } & $\mathrm{NH} 1$ & $\mathrm{NH} 2$ & $\mathrm{NH} 3$ \\
\hline FD & $\otimes$ & $\bullet$ & $\bullet$ \\
\hline FDI & $\otimes$ & & $\otimes$ \\
\hline IS & & $\otimes$ & $\otimes$ \\
\hline II & $\otimes$ & $\bullet$ & $\bullet$ \\
\hline EG & & $\otimes$ & 0.931 \\
\hline Consistency & 0.915 & 0.978 & 0.228 \\
\hline Raw coverage & 0.634 & 0.265 & 0.021 \\
\hline Unique coverage & 0.579 & 0.058 & \\
\hline Solution coverage & & 0.865 \\
\hline Solution consistency & & 0.915 \\
\hline
\end{tabular}

Notes: The symbols represent the same meanings as in Table 3.

other factors are different. Besides, from the results of non-high energy efficiency, configuration NH1 $\left(\sim \mathrm{FD} * \sim \mathrm{FDI}^{*} \sim \mathrm{II}\right)$, the lack of financial development and FDI play a core role together, configuration $\mathrm{NH} 2$ (FD* IS*II* ED), the lack of industrial structure and economic growth play a core role together, and configuration $\mathrm{NH} 3\left(\mathrm{FD}^{*} \sim \mathrm{FDI} *\right.$ IS*II), the absence of FDI and the existence of innovation input play a core role together.

\section{Configuration Analysis}

By comparing the configurations of high energy efficiency and non-high energy efficiency, this paper summarizes the following propositions. First, from the perspective of financial development, good financial development leads to a higher proportion of samples with high energy efficiency ( $\mathrm{H} 2, \mathrm{H} 3, \mathrm{H} 4$, and $\mathrm{H} 5)$, while poor financial development leads to non-high energy efficiency samples as NH1, which original coverage and unique coverage are 0.634 and 0.579 , respectively. This indicates that regions with higher energy efficiency tend to have higher financial development, while those with lower financial development tend to have lower energy efficiency. Moreover, those regions with better financial development mostly have good industrial structures (H3, H4, and H5), which means the improvement of financial efficiency and the optimization of financial system functions can improve financing capacity, and reduce the liquidity risk of funds, improve capital allocation and industrial structure. Meanwhile, the industrial structure of a country or region is changed from heavy industry to light industry, it is beneficial to improve energy efficiency [13]. Therefore, the proposition is proposed:
Proposition 1: Regions with high energy efficiency tend to have better financial development and industrial structure.

According to similar configuration, configuration $\mathrm{H} 3$ and $\mathrm{H} 4$ have the same core conditions, and FDI shows the same effect. This indicates that regions with better financial development and industrial structure often have high-quality FDI, which can cause high energy efficiency. Therefore, regions should consider the role of FDI. Previous studies have drawn three conclusions: First, FDI positively affects energy efficiency [51]. Second, FDI negatively affects energy efficiency. Third, FDI and energy efficiency have an inverted "U" shape [52]. This research echoes the third point. Because in the configuration H3 and H4, FDI does not exist as a core condition, but a peripheral condition. It shows that the deepening of financial markets can increase the savings-investment conversion rate of host countries, strengthen risk management [53], and improve capital allocation efficiency, which can identify investment opportunities, reduce financing costs and investment risks for foreign-funded enterprises, and guide the inflow of FDI.

Besides, configuration $\mathrm{H} 3$ and $\mathrm{H} 4$ define the boundary condition for FDI to improve energy efficiency, namely, good industrial structure. FDI can improve innovation efficiency of local enterprises in host countries, save resources input, optimize and upgrade the industrial structure [36], which contributes to energy efficiency. Configuration NH1 supports this view from the side. Even if the financial development is better, it is difficult to achieve high energy efficiency without a good industrial structure and FDI. Therefore, the proposition is put forward:

Proposition 2: When the financial development is high, regions should adjust the industrial structure while considering the role of FDI to give full play to its spillover effect.

QCA has advantages in analyzing causal asymmetry, namely, high energy efficiency can also be achieved by the presence or absence of financial development (H1) or poor industrial structure (H2). These regions have these characteristics: First, strong investment input, relying on high-level resources such as innovation funds and innovative talents. Second, with the rapid economic growth, more funds are invested in renewable and clean energy technologies to improve energy efficiency [11]. These regions want to obtain high energy efficiency, the better choice is to gradually achieve economic growth, thereby attracting innovative talents, investing in cleaner production, and achieving energy efficiency improvements. Meanwhile, regions should firmly grasp the access standards and entry thresholds, and should not rush to invest in the projects with high energy consumption and pollution due to lack of resources and capacity. Therefore, the proposition is put forward:

Proposition 3: Regardless of financial development status, regions should steadily achieve economic 
growth, attach importance to innovation input, and correctly guide foreign investment.

\section{Conclusions and Suggestions}

\section{Research Conclusion}

In this paper, SBM-undesirable model is used to measure energy efficiency in 30 provinces of China, and promotion model of energy efficiency is explored by fsQCA method. The conclusions are as follows:

First, significant difference in energy efficiency in different regions. At the provincial level, Beijing, Shanghai, Tianjin, Guangdong have higher energy efficiency, while Qinghai, Xinjiang, Ningxia have lower energy efficiency. From the economic regional level, the energy efficiency in the eastern is the highest, the energy efficiency in the central is the second, and the energy efficiency in the western is the lowest. The energy efficiency gradually decreases from the eastern to the central and the western region.

Second, the configurations of energy efficiency have the characteristics of "multiple concurrency" and "principle equifinality". Single factor cannot constitute the necessary condition for energy efficiency, and the "net effect" of any factors on energy efficiency is only valid in specific situation. Different combinations constitute drive paths of high (non-high) energy efficiency. Besides, the configurations of high energy efficiency and non-high energy efficiency is asymmetrical.

Third, regions with better financial development and industrial structure are more likely to achieve high energy efficiency. Other factors play an indispensable role in different situations. Specifically, when financial development and industrial structure are relatively good, regions should consider the role of FDI and give full play to its spillover effect. Regardless of financial development, regions should steadily achieve economic growth and attach importance to innovation input, and should correctly guide foreign investment.

\section{Management Implications}

This study provides inspirations for managers to formulate energy strategies and improve regional sustainable growth. First, managers should pay attention to the calculation of energy efficiency, and environmental changes caused by energy consumption cannot be ignored. Meanwhile, managers should strengthen exchanges and cooperation in different regions, share advanced energy-saving technologies and management experience, and comprehensively improve energy efficiency.

Second, management thinking of the energy efficiency of regional managers should be adjusted from "local optimization" to "overall coordination". Managers should consider the existing resource endowment, and focus on the coordination among conditions according to the "overall coordination" criterion, and make relevant energy policies "in light of local conditions" to form differentiated energy strategies. Besides, managers cannot rely on traditional experience to summarize the reasons for non-high energy efficiency and deduce the reasons for high energy efficiency.

Third, managers need to focus on the investment of innovative technology personnel and innovative technology funds to promote the application of green technologies. Meanwhile, regions should continuously improve the financial system, make full use of financial tools to achieve the reasonable flow of funds, create a good environment to guide high-quality foreign investment and guide the scientific distribution of FDI, realize industrial structure rationalization, and strive to combine the guarantee effect of financial development with the positive effect of FDI technology spillovers, and steadily improve energy efficiency.

\section{Research Contributions}

The contribution of this paper are as follows. First, the effect of energy efficiency extends from single factor to the combination of factors. This paper reveals the matching effect of factors to achieve high (non-high) energy efficiency. Moreover, this paper incorporates fsQCA method into research, enriches method toolbox, and provides a holistic perspective to deepen the cognition of energy efficiency problem. Second, the paper provides a new explanation for the differences in existing research. Previous studies showed the impact of multiple factors or same factor on energy efficiency often lead to different conclusions. This paper finds that energy efficiency is the result of matching effect of multiple factors, which provides a new perspective for explaining differences and eliminates the divergences in existing research.

\section{Limitations and Future Research}

This research has some limitations and needs to be improved in future research. First, the sample was only from China, the conclusions did not have universality in other countries or regions, researchers hope to use samples from other countries or regions to explore this issue. Second, there are many factors that affect energy efficiency, but this paper conducts analysis from financial development, researchers will expand influencing factors such as urbanization and environmental regulation.

\section{Acknowledgements}

This research was funded by the Philosophy and Social Science Foundation of Heilongjiang Province (Grant No.18GLE476), China Postdoctoral Science 
Foundation (Grant No. 2020M670889), Fundamental Research Funds for the Central Universities (Grant No. 3072020CF0702).

\section{Conflict of Interest}

The authors declare no conflict of interest

\section{References}

1. DAI J., CHEN B., HAYAT T., ALSAEDI A., AHMAD B. Sustainability-based economic and ecological evaluation of a rural biogas-linked agro-ecosystem. Renewable and Sustainable Energy Reviews, 41 (1), 347, 2015.

2. CHEN Z., HUANG W., ZHENG X. The decline in energy intensity: Does financial development matter? Energy Policy, 134, 2019.

3. LE T.H., NGUYEN C.P., PARK D. Financing renewable energy development: Insights from 55 countries. Energy Research and Social Science, 68, 2020.

4. LIN B., LIN X. Dilemma between economic development and energy conservation: Energy rebound effect in China. Energy, 45 (1), 867, 2012.

5. ZHANG J., HONG F., WANG H., JIA M., FANG S. Energy efficiency of airlines and its influencing factors: A comparison between China and the United States. Resources Conservation Recycling, 125, 1, 2017.

6. WANG Q. W., ZHOU P., SHEN N. Measuring carbon dioxide emission performance in Chinese provinces: A parametric approach. Renewable Sustainable Energy Reviews, 21 (5), 324, 2013.

7. GUO W., SUN T. Chinese industries' ecological total factor energy efficiency. China Journal of Management, 11 (10), 1690, 2013.

8. LIU Z., ZHANG H., ZHANG Y.J., QIN C.X. How does income inequality affect energy efficiency? Empirical evidence from 33 Belt and Road Initiative countries. Journal of Cleaner Production, 269, 2020.

9. SHAHBAZ M., MALLICK H., MAHALIK M.K., SADORSKY P. The role of globalization on the recent evolution of energy demand in India: Implications for sustainable development. Energy Economics, 55, 52, 2016.

10. MAHLIK M.K., MALLICK H. Energy consumption, economic growth and financial development: Exploring the empirical linkages for India. Journal of Developing Areas, 48 (4), 139, 2014

11. SADORSKY P. Financial development and energy consumption in Central and Eastern European frontier economies. Energy Policy, 39 (2), 999, 2011.

12. ZHU B., ZHANG M., ZHOU Y., WANG P., SHENG J., HE K., WEI Y.M., XIE R. Exploring the effect of industrial structure adjustment on interprovincial green development efficiency in China: A novel integrated approach. Energy Policy, 134, 2019.

13. DANISH S.S., BALOCH M.A., LODHI R.N. The nexus between energy consumption and financial development: estimating the role of globalization in Next-11 countries. Environmental Science Pollution Research International, 25 (19), 18651, 2018.

14. FURUOKA F. Financial development and energy consumption: Evidence from a heterogeneous panel of
Asian countries. Renewable and Sustainable Energy Reviews, 52, 2015.

15. ZHANG Y., WANG W., LIANG L., WANG D., CUI X., WEI W. Spatial-temporal pattern evolution and driving factors of China's energy efficiency under low-carbon economy. Science of the Total Environment, 739, 2020.

16. BI G.B., SONG W., ZHOU P., LIANG L. Does environmental regulation affect energy efficiency in China's thermal power generation? Empirical evidence from a slacks-based DEA model. Energy Policy, 66, 537, 2014.

17. CANH N.P., THANH S.D., NASIR M.A. Nexus between financial development \& energy intensity: Two sides of a coin? Journal of Environmental Management, 270, 2020.

18. YANG Y., CHENG L.W. Stage characteristics of financial development boost energy efficiency. Science Research Management, 40 (4), 125, 2019.

19. XU L., TAN J. Financial development, industrial structure and natural resource utilization efficiency in China. Resources Policy, 66, 2020.

20. PATTERSON M.G. What is energy efficiency? Concepts, indicators and methodological issues. Energy Policy, 24 (5), 377, 1996.

21. BOSSEBOEUF D., RICHARD C. The need to link energy efficiency indicators to related policies: A practical experience based on 20 years of facts and trends in France (1973-1993). Energy Policy, 25 (7), 813, 1997.

22. ZHANG W., PAN X., YAN Y., PAN X. Convergence analysis of regional energy efficiency in china based on large-dimensional panel data model. Journal of Cleaner Production, 142, 801, 2017.

23. GOLDSMITH R.W. Financial Structure and Development. Newhaven. CT: Yale University Press 21-35, 1996.

24. RUBASHKINA Y., GALEOTTI M., VERDOLINI E. Environmental regulation and competitiveness: Empirical evidence on the Porter Hypothesis from European manufacturing sectors. Energy Policy, 83, 288, 2015.

25. PAN X., UDDIN M.K., HAN C., PAN X. Dynamics of financial development, trade openness, technological innovation and energy intensity: Evidence from Bangladesh. Energy, 171 (15), 456, 2019.

26. PARK S., KIM E., HAN N. A study on the green finance and carbon finance. The Journal of International Trade and Commerce, 7 (4), 345, 2011.

27. PONCET S., STEINGRESS W., VANDENBUSSCHE H. Financial constraints in China: Firm-level evidence. China Economic Review, 21 (3), 411, 2010.

28. MUNEMO J. Foreign direct investment and business start-up in developing countries: The role of financial market development. The Quarterly Review of Economics Finance, 65 (8), 97, 2017.

29. TANG C.F., TAN B.W. The impact of energy consumption, income and foreign direct investment on carbon dioxide emissions in Vietnam. Energy, 79, 447, 2015.

30. SCHUMPETER J.A. The theory of Economic Development: An Inquiry into Profits, Capital, Credit, Interest and The Business Cycle. Transaction Publishers Press, 105-111, 1934

31. MiCHALOPOULOS S., LAEVEN L., LEVINE R. Financial innovation and endogenous growth. NBER Working Paper, 153-156, 2013.

32. MASKUS K.E., MILANI S., NEUMANN R. The impact of patent protection and financial development on industrial R\&D. Research Policy, 48 (1), 355, 2019. 
33. CHAVA S., OETTL A., SUBRAMANIAN A. Banking deregulation and innovation. Journal of Financial Economics, 109 (3), 759, 2013.

34. CHOWDHURY R.H., MAUNG M. Financial market development and the effectiveness of R\&D investment: Evidence from developed and emerging countries. Research in International Business and Finance, 26 (2), 258, 2012.

35. FISHER-VANDEN K., JEFFERSON G.H., JINGKUI M., JIANYI X. Technology development and energy productivity in China. Energy Economics, 28 (5), 690, 2006.

36. ASTERIOU D., SPANOUS K. The relationship between financial development and economic growth during the recent crisis: Evidence from the EU. Finance Research Letters, 28, 238, 2018.

37. MISANGYI V.F., GRECKHAMER T., FURNARI S. Embracing causal complexity the emergence of a neoconfigurational perspective. Journal of Management Studies, 43 (1), 225, 2017.

38. RAGIN C. C. Redesigning social inquiry: Fuzzy sets and beyond Chicago: University of Chicago Press 2008.

39. FISS P.C. Building better causal theories: A fuzzy set approach to typologies in organization research. Academy of Management Journal, 54 (2), 393, 2011.

40. MAHONEY J. A tale of two cultures: Contrasting quantitative and qualitative research. Political Analysis, 14 (3), 227, 2006.

41. LACEY R., FISS P.C. Comparative organizational analysis across multiple levels: A set-theoretic approach. Research in the Sociology of Organizations, 26 (26), 91, 2009.

42. LI J.L., LIN B.Q. Green economy performance and green productivity growth in China's cities: Measures and policy implication. Sustainability, 9 (8), 947, 2016.

43. HUANG Y., WANG Y. How does high-speed railway affect green innovation efficiency? A perspective of innovation factor mobility. Journal of Cleaner Production, $265,2020$.
44. JERZMANOWSKI M. Finance and sources of growth: evidence from the U.S. states. Journal of Economic Growth, 22 (1), 97, 2017.

45. PIPEROPOULOS P., WU J., WANG C. Outward FDI, location choices and innovation performance of emerging market enterprises. Research Policy, 47 (1), 232, 2018.

46. HANIF I., FARAZ-RAZA S.M., GAGO-DE-SANTOS P., ABBAS Q. Fossil fuels, foreign direct investment, and economic growth have triggered $\mathrm{CO}_{2}$ emissions in emerging Asian economies: Some empirical evidence. Energy, 171, 493, 2019.

47. LIU Y., LI Z., YIN X. Environmental regulation, technological innovation and energy consumption-a crossregion analysis in China. Journal of Cleaner Production, 203, 885, 2018

48. SYRQUIN M., CHENERY H. Three decades of industrialization. World Bank Economic Review, 3 (2), $145,1989$.

49. CRUZ-CAZARES C., BAYONA-SAEZ C., GARCIAMARCOT. You can't manage right what you can't measure well: Technological innovation efficiency. Research Policy, 42 (6-7), 1239, 2013.

50. MISANGYI V.F., ACHARYA A.G. Substitutes or complements? A configurational examination of corporate governance mechanisms. Academy of Management Journal, 57 (6), 1681, 2014.

51. ELLIOTT R.J.R., SUN P., CHEN S. Energy intensity and foreign direct investment: A Chinese city-level study. Energy Economics, 40, 484, 2013.

52. MIMOUNI K., TEMIMI A. What drives energy efficiency? New evidence from financial crises. Energy Policy, 122, 332, 2018.

53. SONG M.L., TAO J., WANG S.H. FDI, Technology spillovers and green innovation in China: analysis based on Data Envelopment Analysis. Annals of Operations Research, 228 (1), 47, 2015. DOI: https://doi.org/10.1007/ s10479-013-1442-0 